Fibroblasts (Fb) from patients with sarcoidosis (SA) and hypersensitivity pneumonitis (HP) exhibited a lower proliferative capacity compared with Fb obtained from control (CO) and diffuse interstitial fibrosis patients (DIF). Proliferation of Fb from SA or HP patients was suppressed by autologous LPS-stimulated alveolar macrophages (AM) supernatants but not by those from CO patients. Similarly, alveolar macrophages (AM) derived supernatant, obtained from $\mathrm{CO}$, did not suppress the proliferation of SA and HP Fb. AM from SA and HP patients secreted higher amounts of $I L-1 \alpha$ and $\beta$ compared with controls and compared with Fb from SA and HP patients. Steady levels of IL-1 $\alpha$ and $\beta$ mRNA were expressed in unstimulated and stimulated cultures. Fb from SA and HP patients could be stimulated by LPS to secrete significantly higher levels of PGE ${ }_{2}$ than those detected in supernatants from LPS stimulated Fb of DIF patients. Only the proliferation of Fb from SA and HP patients was sensitive to amounts of II-1 equivalent to those detected in the lung of these diseases. As SA and HP are two diseases where irreversible deterioration occurs in only $20 \%$ of the patients, we hypothesize that mediators in the lung may modulate Fb proliferation. IL-1 of AM origin and PGE ${ }_{2}$ of $\mathrm{Fb}$ origin secreted at high levels, may be candidates for this suppression because it was abrogated by anti IL-1 $\beta$ and indomethacin.

Key words: Alveolar fibroblasts, Bronchoalveolar lavage, Interleukin-1, Interstitial lung diseases, Prostaglandin $\mathrm{E}_{2}$

\section{Differential proliferative characteristics of alveolar fibroblasts in interstitial lung diseases: regulative role of IL-1 and $\mathrm{PGE}_{2}$}

\author{
Elizabeth Fireman,, 1 ,CA Shlomo Ben Efraim, ${ }^{2}$ \\ Joel Greif,, ${ }^{1}$ Hava Peretz, ${ }^{3}$ Shmuel Kivity, ${ }^{1}$ \\ Marcel Topilsky, ${ }^{4}$ Yosef Rodrig, ${ }^{4}$ A. Yellin ${ }^{5}$ \\ and Ron N. Apte 6
}

'Departments of Pulmonary and Allergic

Diseases, Ichilov Hospital, 6 Weizmann Street, Tel-Aviv 64239, Israel; 'Department of Human Microbiology, Sackler Faculty of Medicine, Tel-Aviv University, Israel; ${ }^{3}$ Clinical Chemistry, and "Internal Medicine "H", Ichilov Hospital, Tel-Aviv Sourasky Medical Center, Israel; ${ }^{5}$ Department of Thoracic Surgery, Shiba Medical Centre, Israel; ${ }^{6}$ Department of Microbiology and Immunology, Faculty of Health Sciences, Ben Gurion University of the Negev, Beer-Sheva, Israel

CA Corresponding Author

\section{Introduction}

One of the most prominent histologic features of granulomatous and interstitial diseases in the lung is the close proximity of mononuclear cells with fibroblasts or the matrix secreted by them. Several studies characterized mononuclear cell-derived factors that stimulate ${ }^{1,2}$ or inhibit ${ }^{3,4}$ fibroblast growth and secretory functions in vitro. Other researchers have shown that cytokines are released spontaneously by macrophages isolated from lungs of animals exposed to a variety of stimulants, including cytotoxic drugs and mineral dusts, ${ }^{5,6}$ as well as from patients with idiopathic pulmonary fibrosis (IPF) ${ }^{7}$ and sarcoidosis (SA). ${ }^{8}$ Furthermore, alveolar lining fluid collected by pulmonary lavage from patients with pulmonary fibrosis has been shown to contain fibrogenic cytokines, such as TGF $\beta{ }^{9}$ and $\mathrm{TNF} \alpha,{ }^{10}$ pointing to the role of cytokines in vivo. These data suggest that cytokines are present in situ and may mediate the pathological manifestations of interstitial lung diseases. Lately, efforts have been directed towards the identification of macrophage-derived factors which affect fibroblast growth-function, while fewer studies were oriented towards the investigation of the immunoregulatory and pro-inflammatory role of fibroblasts. Recently, it was shown that murine fibroblasts, stimulated by cytokines and LPS, are able to generate IL-1 $\alpha$ activity ${ }^{11,12}$ and that rIL-1 and TNF stimulate normal adult human lung fibroblast to accumulate not to secrete IL-1 $\beta .^{13}$ Moreover, other studies demonstrated that fibroblast strains secrete inflammatory mediators, such as prostaglandin $\mathrm{E}_{2}\left(\mathrm{PGE}_{2}\right)$, interleukin 6 (IL-6), interleukin 8 (IL-8), monocyte chemoattractant peptide (MCP-1) and colony-stimulating factor. ${ }^{14-19}$ As we have previously shown that alveolar fibroblasts can be obtained from long-term cultures of bronchoalveolar cells recovered from patients with $\mathrm{SA}^{20}{ }^{20}$ we decided to further characterize the interactions between alveolar macrophages and alveolar fibroblasts in interstitial lung diseases in an autologous system. Thus, in the present study we assessed the differential secretion of IL-1 and $\mathrm{PGE}_{2}$ by these cells, in comparison with alveolar macrophages and the possible role of these mediators as suppressive agents of fibroplasia and fibrosis in these diseases. 


\section{Patients and Methods}

Study population. Eighteen patients, belonging to three groups were included in this study.

Pulmonary sarcoidosis (SA). Diagnosis was made in six untreated patients (three males and three females, mean age $37 \pm 7$ years), by clinical and roentgenological presentation, a positive Kveim test, or a positive biopsy of non-caseating granuloma. All patients were in Stage II sarcoidosis. None of them was a smoker.

Diffuse interstitial fibrosis (DIF). Three patients (two males and one female, mean age $61 \pm 10$ years). Diagnosis of DIF was made by roentgenological evidence of reticular infiltration and different degrees of interstitial fibrosis, demonstrated by transbronchial biopsy. None of them was a smoker.

Hypersensitivity pneumonitis (HP). Three patients belonged to this group (two males, one female, mean age $48 \pm 6$ years). Roentgenological evidence (X-rays and CT scan) showed reticular nodular pattern with predominant upper zone involvement. Bronchoalveolar lavage (BAL) analysis demonstrated features of a cell-mediated immune response with lymphocytosis. Lung histology was compatible with HP but no attempt was made to characterize the sensitizing antigens. None of them was a smoker.

Control. Six patients (three males and three females, mean age $44 \pm 18$ years) were admitted for investigation due to persistent cough. All of them presented chest roentgenograms within normal limits. None of them was a smoker.

None of the patients received any medicaments prior to the study. Written consent was obtained from each subject before bronchoscopy. Characterization of cell population present in BAL and pulmonary function test parameters of all patients examined are summarized in Table 1.
Methods:

Bronchoalveolar lavage (BAL). BAL was performed using a flexible fibre optic bronchoscope (BF-B2; Olympus Optical Co., Ltd, Tokyo, Japan) as previously described. ${ }^{21}$ The cells were recovered by gentle aspiration. The percentage of lavage fluid $( \pm S D)$ recovered from each group of patients was as follows: $67 \pm 10 \%$ from CO and $58 \pm 8 \%$ from ILD cases. The average total cells recovered was $5 \pm 1 \times 10^{6}$ cells from $\mathrm{CO}$ and $17 \pm 7 \times 10^{6}$ cells from ILD patients.

Preparation of $A M$ and $A M$ supernatants. AM were prepared as previously described. ${ }^{21}$ Differential counts were performed on a Giemsa stained cytocentrifuge preparation (Cytospin; Shandon, Southern Products Ltd, Runcorn, Cheshire, UK), by counting a minimum of 500 cells. Cells were adjusted to a final concentration of $10^{6}$ cells $/ \mathrm{ml}$ in RPMI 1640 medium, supplemented with $10 \%$ heat inactivated FCS, 1\% L-glutamine, and 1\% streptomycin, penicillin, mycostatin complete medium (Biological Industries, Beit Haemek, Israel). The AM were purified by adherence in a $5 \% \mathrm{CO}_{2}$ humidified atmosphere for $1 \mathrm{~h}$ at $37^{\circ} \mathrm{C}$. Identification of macrophages was done by morphology and nonspecific esterase staining and counted with an objective micrometer (Olympus Optical Co., Ltd, Tokyo, Japan). The adherent cell population contained more than $90 \%$ AM.

AM were cultured in 3-cm diameter plastic Petri dishes (Sterilin, Hounslow, Middlesex, UK) for either $24 \mathrm{~h}$ or $72 \mathrm{~h}$. The $24 \mathrm{~h}$ period was found to be optimal for testing the production if IL-1 in the presence of lipopolysaccharide (LPS-Escherichia coli 055:B5; Difco Laboratories, Detroit, USA; $10 \mu \mathrm{g} / \mathrm{ml}$ ) stimulated cultures. The $72 \mathrm{~h}$ period was chosen as the optimal time for release of $\mathrm{PGE}_{2}$ in unstimulated cultures. Supernatants were recovered, filtered (Acrodisc $0.2 \mu$; Gelman Sciences) and stored at $-70^{\circ} \mathrm{C}$ until determination for IL-1, and not longer than 2 weeks for $\mathrm{PGE}_{2}$.

Table 1. BAL cells characteristics and pulmonary function tests (PFT) in all patients

\begin{tabular}{|c|c|c|c|c|c|c|c|c|c|c|}
\hline Patients $^{a}$ & Mac & Ly & Bas & Eos & Neut & DLCO & FVC & $\mathrm{FEV}_{1}$ & $\mathrm{FEV}_{1} / \mathrm{FVC}$ & TLC \\
\hline \multicolumn{11}{|l|}{ SA (6) } \\
\hline $\begin{array}{l}\text { Mean } \pm \text { SD } \\
\text { HP (3) }\end{array}$ & $51 \pm 15$ & $48 \pm 15^{\star}$ & $0.6 \pm 0.4$ & $0.5 \pm 0.2$ & $0.8 \pm 0.6$ & $99 \pm 14^{\star \star}$ & $99 \pm 9$ & $87 \pm 10$ & $102 \pm 6$ & $97 \pm 11$ \\
\hline $\begin{array}{l}\text { Mean } \pm \text { SD } \\
\text { DIF (3) }\end{array}$ & $40 \pm 8$ & $58 \pm 12^{*}$ & $1.9 \pm 1$ & $0.9 \pm 1.3$ & $0.8 \pm 0.4$ & $114 \pm 22^{* \star}$ & $103 \pm 14$ & $104 \pm 10$ & $106 \pm 3$ & $103 \pm 15$ \\
\hline $\begin{array}{l}\text { Mean } \pm \text { SD } \\
\text { CO (6) }\end{array}$ & $70 \pm 8$ & $13 \pm 13$ & - & $8.4 \pm 8^{\star \star \star}$ & $12 \pm 8^{\star \star \star}$ & $69 \pm 9$ & $76 \pm 8$ & $77 \pm 9$ & $106 \pm 6$ & $86 \pm 7$ \\
\hline Mean \pm SD & $86 \pm 5$ & $13 \pm 5$ & - & - & - & $103 \pm 12$ & $99 \pm 3$ & $101 \pm 12$ & $109 \pm 5$ & $102 \pm 5$ \\
\hline
\end{tabular}

${ }^{\star} p<0.0001$ compared with $\mathrm{CO}$ group.

${ }^{\star \star} p<0.001$ compared with DIF group.

${ }^{\star \star \star} p<0.001$ compared with $\mathrm{CO}$ group.

$\mathrm{Mac}=$ macrophages; $\mathrm{Ly}=$ lymphocytes; Bas = basophils; Eos = eosinophils; Neut = neutrophils; $\mathrm{DLCO}=$ diffusion lung carbon oxide; FVC

$=$ forced vital capacity; FEV 1 = forced vital capacity second one; TLC = total lung capacity.

PFT were performed in all patients prior to the BAL.

Differential counts were performed by counting 500 cells of a Giemsa stain cytoprep as described in Patients and Methods. 
Preparation of alveolar fibroblasts. The fibroblast line was derived from the bronchoalveolar cells as previously described..$^{20}$ First clones of proliferating fibroblasts appeared after 2-3 weeks of incubation in 3-cm diameter plastic Petri dishes (Sterilin, Hounslow, Middlesex, UK). After reaching confluence, usually 5-6 weeks later, the explant tissue was removed with trypsin-EDTA Type B (Biological Industries, Beit Haemek, Israel) for $10 \mathrm{~min}$ and cells were split 1:2 at confluency in $25 \mathrm{~cm}^{2}$ tissue plastic culture flasks (Sterilin, Hounslow, Middlesex, UK). In all experiments the cells used were from passages 4-7.

Preparation of pulmonary fibroblasts. Stable lines of human pulmonary fibroblasts were used a control cells. Lung specimens from pneumonectomy specimens from patients with thoracic malignancies or benign lesions were minced into pieces of $2-4 \mathrm{~mm}$ and incubated in $1 \times 5 \mathrm{~cm}$ Petri dishes (Sterilin, Hounslow, Middlesex, UK) containing $3 \mathrm{ml}$ of complete DMEM. Every $72 \mathrm{~h}$ the non-adherent cells were removed by washing with PBS and fresh media was added. After 2 weeks, cultures reached confluence and the cells were split and used as described above.

Preparation of Fb supernatants and Fb proliferation test. $\mathrm{Fb}$ derived supernatants were obtained from $24 \mathrm{~h}$ LPS-stimulated $\mathrm{Fb}$ cultures cultured for $24 \mathrm{~h}$ with or without LPS. Aliquots of the supernatants were frozen at $-70^{\circ} \mathrm{C}$ until used. Proliferation test was performed as previously described. ${ }^{20}$ Briefly, $100 \mu \mathrm{l}$ of $\mathrm{Fbs}$ suspended at $10^{5} \mathrm{Fb} / \mathrm{ml}$ were allowed to attach for 1-2 h. Aliquots $(50 \mu \mathrm{l})$ of supernatants of LPSstimulated AM were added. Proliferation was assessed after $72 \mathrm{~h}$, and pulsed with $1 \mu \mathrm{Ci}{ }^{3} \mathrm{H}-\mathrm{Tdr}$ ( $48 \mu \mathrm{Ci} / \mathrm{nmol}$ specific activity, Rotem Industries Ltd, Beer-Sheva, Israel) for the last $16 \mathrm{~h}$ of culture. The proliferation of $\mathrm{Fb}$ in the presence of $\mathrm{AM}$ supernatants was compared with that of Fbs DMEM with a final concentration of $100 \mu \mathrm{g} / \mathrm{ml} \mathrm{LPS}$.

Assay of prostaglandin and IL-1 production. Aliquots of $\mathrm{AM}$ and $\mathrm{Fb}$ supernatants $(24 \mathrm{~h}$ production) were assayed for $\mathrm{PGE}_{2}$ by a radioimmunoassay (Advanced Magnetic Inc., MA, USA) and IL- $1 \alpha$ and IL- $1 \beta$ production by a RIA Kit (Amerlex-M ${ }^{\mathrm{TM}}$ Magnetic separation, Amersham International PLC, Amersham, UK).

Isolation of $m R N A$ transcripts. RNA was extracted by $100 \mu \mathrm{l}$ of $4.0 \mathrm{M}$ guanidium thiocyanate (GuSCN Sigma Chemical Co., St Louis, USA) from adherent $10^{6}$ cells/ $\mathrm{ml}$ stimulated $(10 \mu \mathrm{g}$ LPS $+10 \mathrm{ng} / \mathrm{ml} \mathrm{IL-} 1 \alpha$ and $\beta$ for $24 \mathrm{~h}$ and non-stimulated $\mathrm{AFb}$. The mixture was overlaid on to $100 \mu \mathrm{l}$ of $5.7 \mathrm{M} \mathrm{CsCl}$ and RNA was isolated after overnight ultracentrifugation at 35000 r.p.m. (Kontron Institute, Zurich, Switzerland) at $15^{\circ} \mathrm{C}$. The pellet recovered by centrifugation was resuspended in $100 \mu \mathrm{l}$ DEPC water, $300 \mu \mathrm{l}$ pure ethanol and $30 \mu \mathrm{l}$ $3.0 \mathrm{M}$ sodium acetate. The RNA pellet $\left(30^{\prime}\right.$ at 15000 r.p.m.) was washed (100 $\mu$ l 80\% ethanol) and amplified using the reverse transcription-mix [RT mix: $3 \mu l 200 \mathrm{U} / \mu \mathrm{l}$ MMLV, moloney murine leukaemia virus-RT (BRL, Bethesda Research Laboratory, Gaithesburg, MD, USA), $1 \mu \mathrm{l} 40 \mathrm{U} / \mu \mathrm{l}$ RNAasin, $6 \mu \mathrm{l}$ 5XMMLV buffer, $3 \mu \mathrm{l}$ random primers (Promega CA, Madison, USA), $3 \mu \mathrm{l}$ of $1 \mathrm{mg} / \mathrm{ml}$ BSA (Sigma Chemicals Co., St Louis, USA) $1.5 \mu \mathrm{l}$ of $10 \mathrm{mM}$ dNTP mixPharmacia, Fine Chemicals AB, Uppsala, Sweden). Each sample contained $17.5 \mu \mathrm{l}$ and the reaction was performed for $1 \mathrm{~h}$ at $42^{\circ} \mathrm{C}$.

PCR assay. cDNA fragments were amplified (GeneAmp-Clontech Laboratories Inc., Palo Alto, CA, USA) in a polymerase chain reaction (PCR) mix containing $8 \mu \mathrm{l}$ dNTPs mix $1.25 \mathrm{mM}$ (Pharmacia Fine Chemicals AB, Uppsala, Sweden) and $0.25 \mu \mathrm{l} \mathrm{Taq}$ polymerase, $5 \mathrm{U} / \mu \mathrm{l}$ (Promega CA, Madison, USA) using thermal cycler cells (PT-100 MJ Research Inc., OSP, Cambridge MA, USA). $\beta$ actin mRNA was evaluated concurrent with IL- $1 \alpha$ and $\beta$ mRNA as an internal control. Products of the combined reverse transcription-polymerase reaction ( $8 \mu \mathrm{l}$ PCR product and $2 \mu$ of gel loading buffer) were fractionated by electrophoresis in agarose stained with ethidium bromide and validated by matching predicted size 174/HaeIII digest (Pharmacia Fine Chemicals AB, Uppsala, Sweden).

Statistics. Student's $t$-test was used for statistical evaluations using the Epistat Software, (C) 1984, T.L. Gustafson. The results are expressed as mean \pm SD and values less than 0.05 were considered to be significant.

\section{Results}

Effect of AM supernatants on the proliferation of fibroblasts: The basic proliferation rate of $\mathrm{Fb}$ from SA and HP patients was shown to be significantly lower than that of $\mathrm{Fb}$ in the $\mathrm{CO}$ group (Table 2).

AM-derived supernatants were tested for effects on the proliferation of $\mathrm{Fb}$ in an autologous culture set-up and in presence of $\mathrm{AM}$ supernatant of $\mathrm{CO}$ patients (Fig. 1) and on normal $\mathrm{Fb}$ lines (Fig. 2). The AM supernatants of SA and HP suppressed the prolifera-

Table 2. Proliferation rates of $\mathrm{Fbs}^{\mathrm{a}}$

\begin{tabular}{llcc}
\hline Patient & SA-Fb & HP-Fb & CO-Fb \\
\hline 1 & $7753 \pm 1007$ & $32677 \pm 5257$ & $62466 \pm 5528$ \\
2 & $9399 \pm 297$ & $10509 \pm 1256$ & $28437 \pm 2687$ \\
3 & $1801 \pm 437$ & $9182 \pm 1609$ & $25347 \pm 5630$ \\
4 & $7613 \pm 1007$ & & $30271 \pm 982$ \\
5 & $6047 \pm 268$ & & $46776 \pm 2286$ \\
6 & $2633 \pm 853$ & & - \\
Mean \pm SD & $5874 \pm 2771^{*}$ & $17459 \pm 10776^{\star *}$ & $38659 \pm 14033$
\end{tabular}

a Fibroblasts were cultured in complete DMEM as described in Patients and Methods. Thymydine uptake was measured after incubation of $72 \mathrm{~h}$.

${ }^{\star} p<0.001$ compared with $\mathrm{CO}$.

${ }^{\star \star} p<0.001$ compared with $\mathrm{CO}$. 

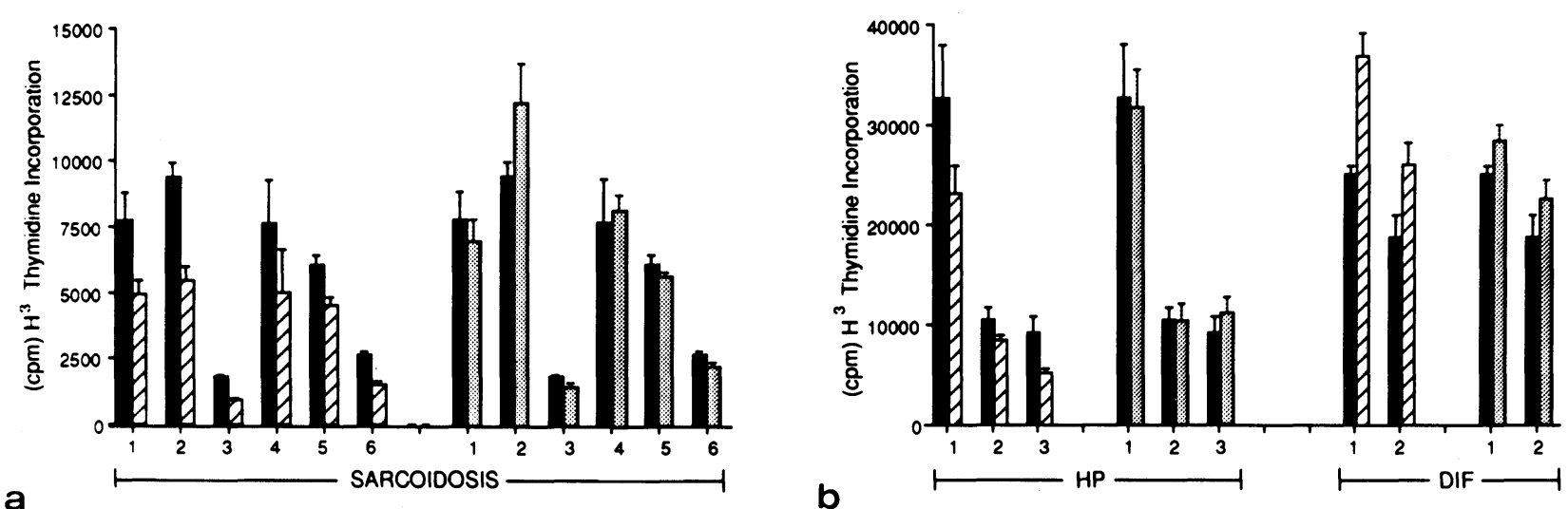

FIG 1. Effects of AM-derived supernatants on the proliferation of autologous Fb. Fb were incubated for $72 \mathrm{~h}$ in DMEM (2\% FCS, antibiotics, antimycotic) in the presence or absence of autologous supernatants. (a) Six cases: $\square$ Fb incubated in DMEM; $\mathbb{Z}$ Fb incubated in DMEM + autologous AM supernatant of SA patients; Fb incubated in DMEM + AM supernatant of CO patients. (b) Left side, three HP cases; right, two DIF cases: $\mathrm{Fb}$ incubated in DMEM

Fb incubated in DMEM + autologous AM supernatant of HP and DIF patients; Fb incubated in DMEM + AM supernatant of CO patients.
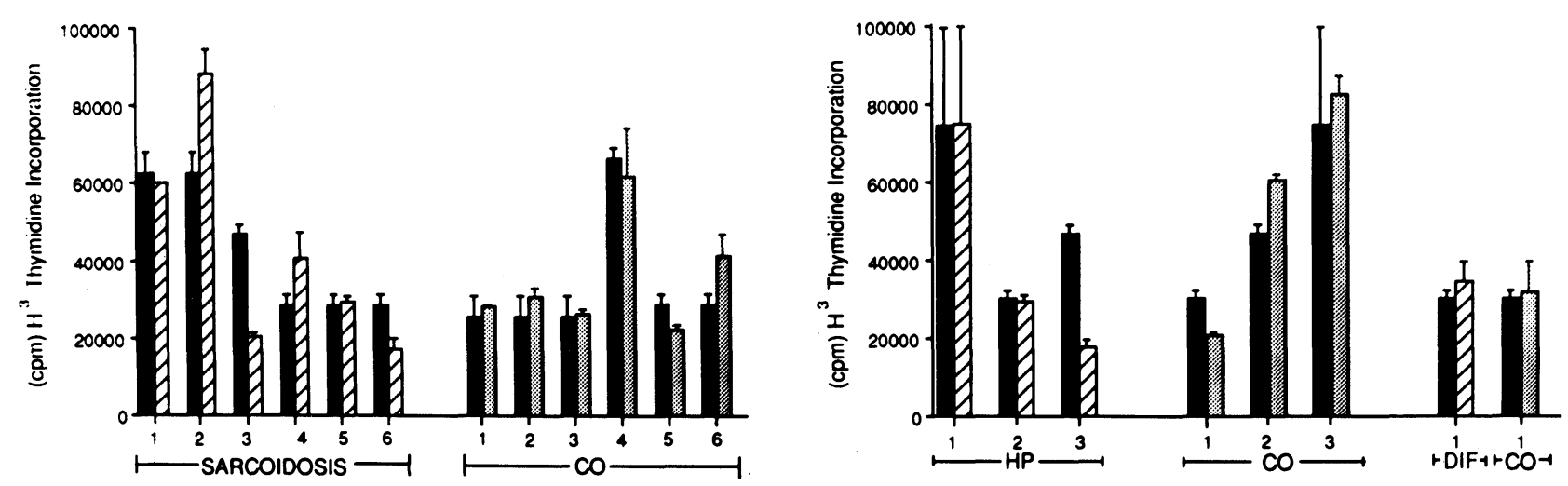

a

b

FIG 2. Effects of AM-derived supernatants on the proliferation of control Fb. Fb were incubated for $72 \mathrm{~h}$ in DMEM (2\% FCS, antibiotics, antimycotic) in the presence or absence of supernatants. (a) Six cases: $\mathrm{Fb}$ incubated in DMEM; $\mathbb{Z}$ Fb incubated in DMEM + AM supernatants of SA patients; incubated in DMEM + AM supernatants of CO patients. (b) From left to right: HP three cases; CO three cases; DIF and CO one case: $\mathrm{Fb}$ incubated in DMEM; Fb incubated in DMEM + AM supernatants of HP and DIF; $\mathrm{Fb}$ incubated in DMEM + AM supernatants of patients.

tion of autologous $\mathrm{Fb}$ by $38 \pm 7 \%$ (Fig. 1a, patients $1-6$, left panel) and $31 \pm 10 \%$ (Fig. $1 \mathrm{~b}$, patients $1-3$, left panel), respectively. In contrast, CO AM-derived supernatants suppressed proliferation by only $13 \pm$ $5 \%$ in four cases (Fig. 1a, patients 1, 3, 5 and 6, right panel) and enhanced by $30 \pm 1 \%$ in two cases (Fig. 1a, patients 2 and 4, right panel) when tested on $\mathrm{Fb}$ of SA. When CO AM supernatants were tested on $\mathrm{HP}-\mathrm{Fb}, 3 \%$ suppression in two cases (Fig. 1b, patients 1 and 2, right panel) and 20\% enhancement in the third case $(p<0.001$ between patients groups and controls). The SA-AM derived supernatants exerted a differential effect when tested on normal Fb: suppression of $34 \pm 22 \%$ in three cases (Fig. 2a, patients 1,3 and 6, left panel) and enhancement in three others $29 \pm 18 \%$ (Fig. 2a, patients 2, 4 and 5, left panel). A similar pattern was seen in the HP group. Supernatants derived from DIF patients enhanced the proliferation of $\mathrm{Fb}$ in all cases tested.

Thus, in the autologous culture set-up, AM-derived supernatants from SA and HP patients exerted significant suppression on the proliferative capacity of alveolar $\mathrm{Fb}$, which was much less pronounced when tested on normal $\mathrm{Fb}$. In addition, AM-derived supernatants from control or DIF patients, did not exert a suppressive effect on $\mathrm{Fb}$ proliferation.

Analysis of $I L-1 \alpha, I L-1 \beta$ and $P G E_{2}$ levels in $A M$ and $F b$ supernatants: LPS-induced supernatants from AM and $\mathrm{Fb}$ were tested for their ability to secrete IL- $1 \alpha$, $\beta$ and $\mathrm{PGE}_{2}$. As shown in Tables 3 and 4 , the levels of IL- $\alpha$ and $\beta$ of stimulated SA and HP AM,

Table 3. IL-1 $\alpha^{\mathrm{a}}$ levels in AM and Fb supernatants

\begin{tabular}{llrlrr}
\hline Diagnosis & \multicolumn{2}{c}{ AM } & & \multicolumn{2}{c}{ Fb } \\
\cline { 2 - 3 } \cline { 5 - 6 } \cline { 5 - 6 } & \multicolumn{1}{c}{-LPS } & +LPS & & -LPS & +LPS \\
\hline SA (6) & $0.17 \pm 0.03^{*}$ & $0.78 \pm 0.71^{\star}$ & & $0.16 \pm 0.05$ & $0.17 \pm 0.05$ \\
HP (3) & $0.13 \pm 0.04^{*}$ & $0.5 \pm 0.2^{\star *}$ & & $0.14 \pm 0.05$ & $0.2 \pm 0.04$ \\
DIF (3) & $0.08 \pm 0.02$ & $0.16 \pm 0.02$ & & $0.14 \pm 0.15$ & $0.16 \pm 0.01$ \\
CO (6) & $0.05 \pm 0.007$ & $0.18 \pm 0.04$ & & $0.18 \pm 0.04$ & $0.18 \pm 0.02$ \\
\hline
\end{tabular}

a IL-1 $\alpha$ was measured in Fb supernatants by RIA as described in Patients and Methods. Results are expressed as concentration of IL-1 (ng/ml).

${ }^{*} p<0.05$ compared with $\mathrm{CO}$

${ }^{\star *} p<0.001$ compared with $\mathrm{CO}$. 
Table 4. IL-1 $\beta^{\mathrm{a}}$ levels in AM and Fb supernatants

\begin{tabular}{lcclcc}
\hline \multirow{2}{*}{ Diagnosis } & \multicolumn{2}{c}{ AM } & & \multicolumn{2}{c}{ Fb } \\
\cline { 2 - 3 } \cline { 5 - 6 } & -LPS & +LPS & & LPS & +LPS \\
\hline SA (6) & $0.09 \pm 0.04^{\star \star}$ & $2.1 \pm 2.0^{*}$ & & $0.14 \pm 0.04$ & $0.15 \pm 0.04$ \\
HP (3) & $0.08 \pm 0.03^{\star \star}$ & $1 \pm 0.6^{\star \star}$ & & $0.13 \pm 0.04$ & $0.17 \pm 0.04$ \\
DIF (3) & $0.08 \pm 0.02$ & $0.16 \pm 0.02$ & & $0.18 \pm 0.06$ & $0.17 \pm 0.02$ \\
CO (6) & $0.07 \pm 0.02$ & $0.17 \pm 0.08$ & & $0.12 \pm 0.04$ & $0.12 \pm 0.01$
\end{tabular}

a IL-1 $\beta$ was measured in Fb supernatants by RIA as described in Patients and Methods. Results are expressed as concentration of $\mathrm{IL}-1$ (ng/ml).

${ }^{*} p<0.05$ compared with $\mathrm{CO}$ and DIF.

${ }^{* *} p<0.001$ compared with $\mathrm{CO}$ and DIF.

were significantly higher than those of $\mathrm{CO}$ cultures $(2.1 \pm 2.0$ and $1 \pm 0.6 \mathrm{ng} / \mathrm{ml}$, compared with $0.17 \pm$ $0.08 \mathrm{ng} / \mathrm{ml}$ for IL-1 $\beta$, and $0.8 \pm 0.7$ and $0.5 \pm 0.2$ $\mathrm{ng} / \mathrm{ml}$ compared with $0.2 \pm 0.04 \mathrm{ng} / \mathrm{ml}$ for IL- $1 \alpha$, $p<0.05$ compared with CO).

LPS did not affect the secretion if IL- $1 \alpha$ and IL-1 $\beta$ and only baseline levels of those cytokines were produced by $\mathrm{Fb}$ irrelevant of their source. In contrast, when $\mathrm{PGE}_{2}$ secretion was assessed (Table 5) it was demonstrated that LPS-stimulated $\mathrm{Fb}$ of $\mathrm{SA}$ and $\mathrm{HP}$ patients generated significantly higher levels of $\mathrm{PGE}_{2}$ $(0.36 \pm 0.24$ and $0.59 \pm 0.27 \mathrm{ng} / \mathrm{ml}$ in stimulated supernatants of SA and HP patients compared with $0.16 \pm 0.12$ and $0.23 \pm 0.19 \mathrm{ng} / \mathrm{ml}$ in unstimulated cultures). The high levels of $\mathrm{PGE}_{2}$ secreted by stimulated $\mathrm{Fb}$ in $\mathrm{SA}$ and $\mathrm{HP}$ were significantly higher than those found in $\mathrm{Fb}$ recovered from DIF patients $(0.36$ \pm 0.24 and $0.59 \pm 0.27 \mathrm{ng} / \mathrm{ml}$ in SA and $\mathrm{HP}$, compared with $0.06 \pm 0.03 \mathrm{ng} / \mathrm{ml}$ in DIF, $p<0.05)$.

Detection of IL-1 $\alpha$ and IL-1 $\beta$ mRNA transcripts in Fb: In order to assess whether the IL- $1 \alpha$ and IL- $1 \beta$ genes are expressed in $\mathrm{Fb}$ of these diseases, we assessed the mRNA transcripts by PCR. IL- $\alpha$ and IL- $1 \beta$ transcripts were constitutively found in stimulated, as well as non-stimulated, Fbs (Fig. 3a, b, c and d).

Effects of exogenous $I L-1 \beta$ on Fb proliferation: Exogenous IL-1 $\beta$ (concentrations in the range of 0.3-1000 $\mathrm{ng} / \mathrm{ml}$ ), were added to $\mathrm{Fb}$ cultures and proliferation was assessed by the tritiated thymidine incorporation. IL-1 $\beta$, at concentrations of $0.35-62.5$ $\mathrm{ng} / \mathrm{ml}$ (Fig. 4a) and 0.35-125 ng/ml (Fig. 4b) significantly suppressed the basic proliferation rate of $\mathrm{Fb}$ by $46 \pm 1.4 \%$ and $39 \pm 0.9 \%(p<0.001)$ compared with proliferation of $\mathrm{Fb}$ in complete medium (Fig. $4 \mathrm{a}$ and b). These concentrations include the range of IL-1 $\beta$ by AM of SA and HP patients $(4-0.8 \mathrm{ng} / \mathrm{ml})$. As a general trend in Fbs of the $\mathrm{CO}$ group, no suppressive activity was observed at minute concentrations of IL$1 \beta$ (Fig. 4c). The modulatory effects of IL-1 $\beta$ were abrogated by anti-IL-1 antibodies or indomethacin (Table 6). A clear reversion of the suppression was achieved in the SA and HP group, but not in the CO and DIF groups.

\section{Discussion}

$\mathrm{AM}$ are present within the alveoli and bronchioli while the fibrosis occurs in the interstitium. However, it is feasible to assume that AM affect the process of fibrosis because of their close proximity. The outcome of a number of interstitial lung diseases (ILD) results in severe pulmonary fibrosis. In contrast, patients with SA or HP, manifesting inflammatory or granulomatous diseases, usually heal without excessive scarring. In the present study, we assessed the fibroblast-macrophage interactions in ILD, in an attempt to understand the differential outcome of the diseases. We assessed the proliferative capacity of $\mathrm{Fb}$ and the secretion of cytokines/inflammatory products by $\mathrm{AM}$ and $\mathrm{Fb}$, the latter being the target cells in these diseases.

We showed (Table 2) that $\mathrm{Fb}$ recovered from SA and HP, display significantly lower rates of background proliferation, compared with $\mathrm{Fb}$ recovered from normal tissue specimens even after serial passages for up to 2 months. The existence of $\mathrm{Fb}$ populations from fibrotic lungs which retain enhanced proliferative potential in culture, have already been reported ${ }^{22,23}$ together with reports on decreased $^{24}$ or increased ${ }^{25}$ cytokine production by fibroblasts in chronic GVHD (graft versus host dis-

Table 5. $P G E_{2}{ }^{a}$ levels in $A M$ and $F b$ supernatants

\begin{tabular}{lccccc}
\hline Diagnosis & \multicolumn{3}{c}{ AM } & & \multicolumn{2}{c}{$\mathrm{Fb}$} \\
\cline { 2 - 3 } \cline { 5 - 6 } & -LPS & +LPS & & -LPS & \multicolumn{1}{c}{+ LPS } \\
\hline SA (6) & $0.06 \pm 0.02$ & $0.31 \pm 0.3$ & & $0.16 \pm 0.12^{\star}$ & $0.36 \pm 0.24^{\star \star \star}$ \\
HP (3) & $0.09 \pm 0.02$ & $0.27 \pm 0.14$ & & $0.23 \pm 0.19$ & $0.59 \pm 0.27$ \\
DIF (3) & $0.5 \pm 0.3$ & $1.2 \pm 0.5^{\star * \star *}$ & $0.6 \pm 0.03$ & $0.06 \pm 0.03^{\star *}$ \\
CO (6) & $0.04 \pm 0.01$ & $0.41 \pm 0.31$ & & $0.49 \pm 0.20$ & $0.46 \pm 0.20$ \\
\hline
\end{tabular}

a $\mathrm{PGE}_{2}$ was measured in Fb supernatants by RIA as described in Patients and Methods. $\mathrm{PGE}_{2}$ levels are expressed in $\mathrm{ng} / \mathrm{ml}$.

${ }^{*} p<0.05$ compared with $\mathrm{CO}$.

${ }_{* \star} p<0.01$ compared with $\mathrm{CO}$.

${ }_{* \star \star} p<0.05$ compared with DIF.

${ }^{\star * \star \star} p<0.02$ compared with $\mathrm{CO}, \mathrm{SA}$ and HP. 

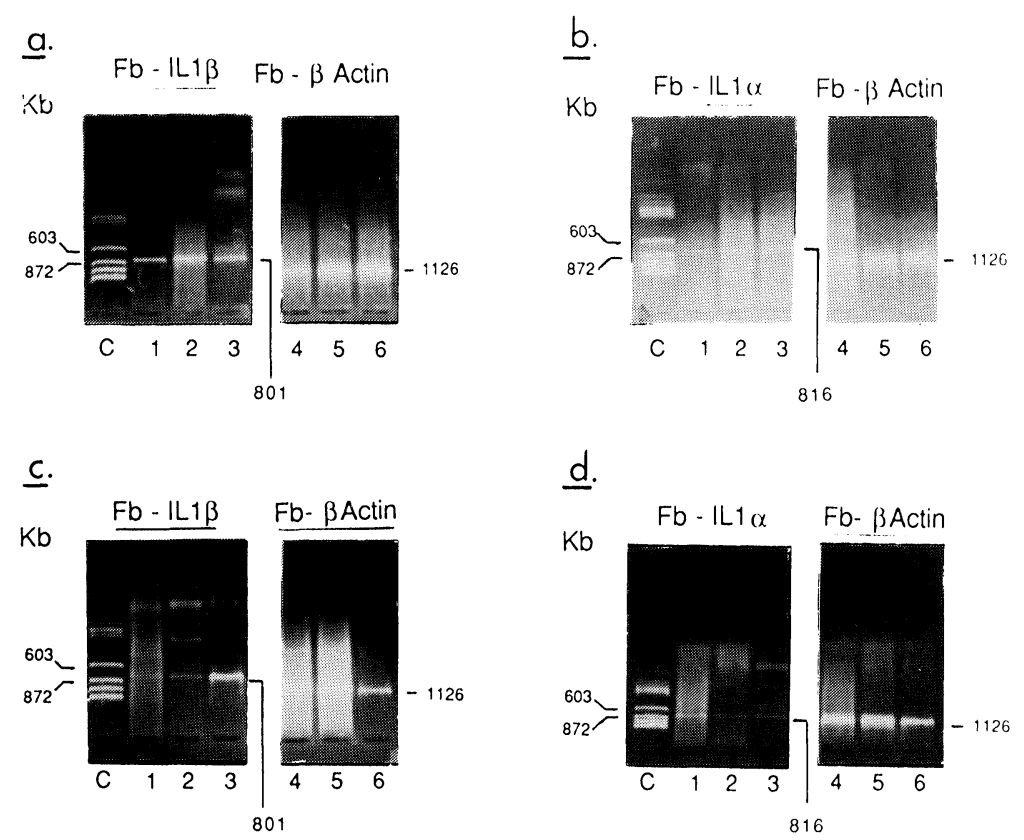

FIG. 3. Detection of IL-1 $\alpha$ and IL-1 $1 \beta$ mRNA transcripts in Fb. mRNA was isolated as described in Patients and Methods and reverse transcripted in a RT reaction. cDNA fragments were amplified in a PCR reaction. (a,b) IL-1 $\alpha$ and $\beta$ transcripts of $\mathrm{Fb}$ in $\mathrm{SA} ;(\mathrm{c}, \mathrm{d}) \mathrm{IL}-1 \alpha$ and $\beta$ transcripts of $\mathrm{Fb}$ in $\mathrm{CO}$. Each experiment is compared with positive transcription of $\beta$ actin.
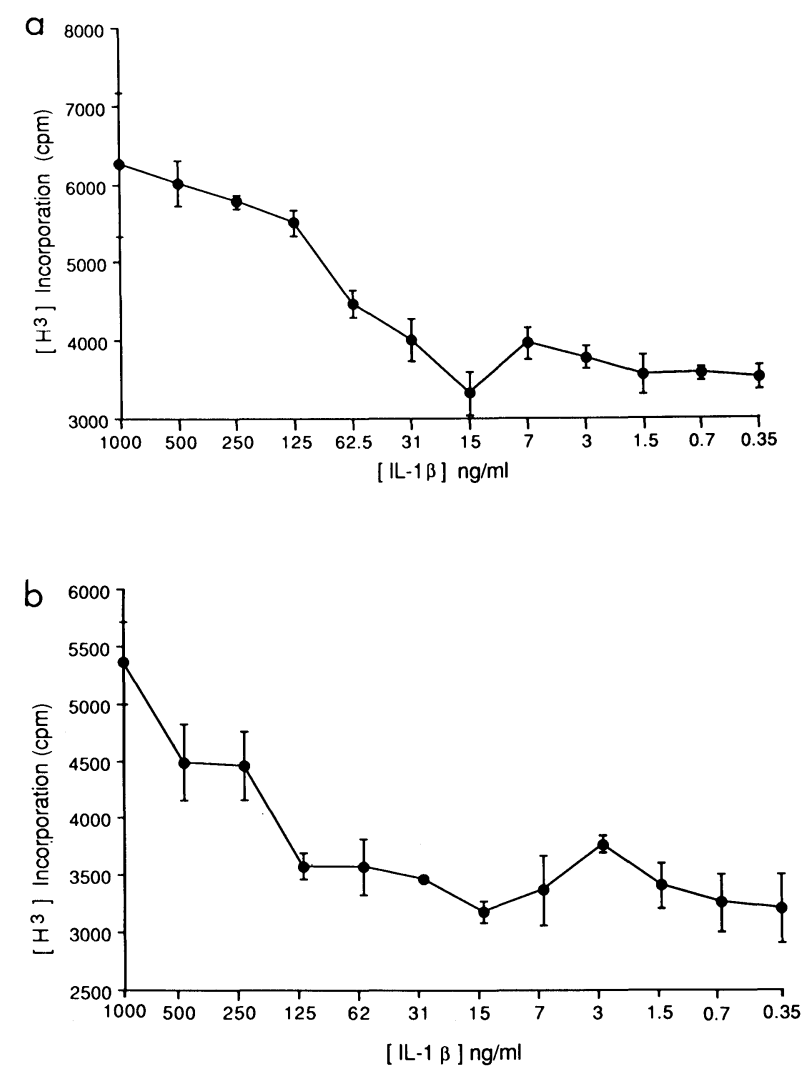

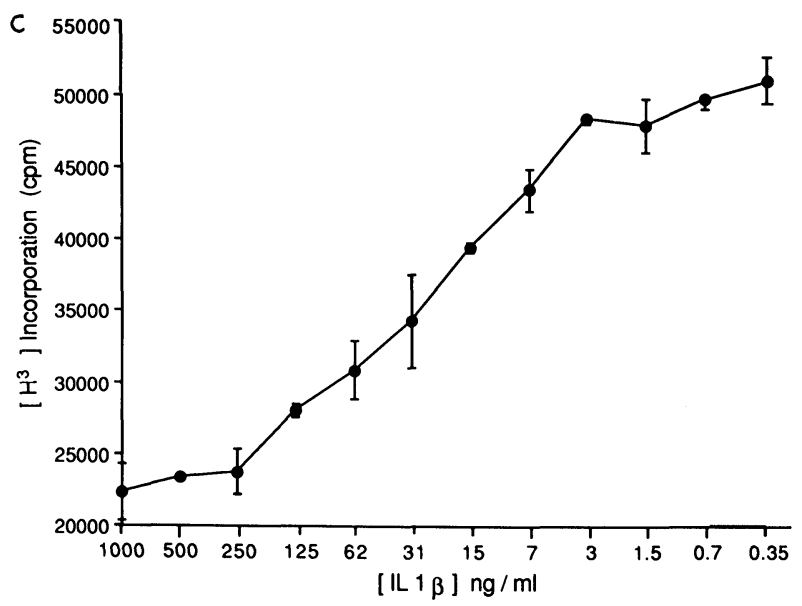

FIG. 4. Effect of exogenous IL- $\beta$ on the proliferation of $\mathrm{Fb}$. (a) SA Fb (basic proliferation of $\mathrm{Fb}=6600 \pm 545 \mathrm{cpm}$ ). (b) $\mathrm{HP} \mathrm{Fb}$ (basic proliferation of $\mathrm{Fb}=5429 \pm 345 \mathrm{cpm}$ ). (c) CO Fb (basic proliferation of $\mathrm{Fb}=54173 \pm 1327$ cpm). 
Table 6. Effect of indomethacin and anti-IL-1 $\beta$ antibodies on IL-1 $\beta$ induced suppression on Fb proliferation ${ }^{\mathrm{a}}$

\begin{tabular}{lcccc}
\hline & SA & HP & DIF & CO \\
\hline Medium & $4478 \pm 235$ & $5430 \pm 343$ & $15726 \pm 150$ & $54173 \pm 1327$ \\
IL-1 $\beta(1.5 \mathrm{ng} / \mathrm{ml})$ & $3561 \pm 257$ & $3404 \pm 8$ & $12500 \pm 500$ & $47808 \pm 1866$ \\
IL-1 $\beta(1.5 \mathrm{ng} / \mathrm{ml})$ & $7516 \pm 354$ & $5062 \pm 352$ & $8306 \pm 914$ & $48977 \pm 9649$ \\
+ Ind $(1 \mu \mathrm{g} / \mathrm{ml})$ & & & & \\
IL-1 $(1.5 \mathrm{ng} / \mathrm{ml})$ & $5508 \pm 142$ & $10782 \pm 1052$ & $2648 \pm 108$ & $46689 \pm 780$ \\
+ anti-IL-1 $(20 \mu \mathrm{g} / \mathrm{ml})$ & & & & \\
\hline
\end{tabular}

${ }^{a} \mathrm{cpm}$ of ${ }^{3}[\mathrm{H}]$ thymidine incorporation of fibroblasts. Indomethacin and anti-IL-1 were added and cells were incubated for $72 \mathrm{~h}$. The experiment was repeated three times with similar results.

ease) and rheumatoid arthritis, respectively. The possibility that alveolar $\mathrm{Fb}$ differed from control $\mathrm{Fb}$ in the method of recovery seems unlikely, as it was shown by Davis et al. ${ }^{26}$ that alveolar lavage fibroblasts displayed similar distributions of interdivision time as in foetal and adult lung tissue fibroblasts.

We showed also that AM-derived supernatants suppressed the proliferation of autologous $\mathrm{Fb}$, recovered from patients with SA and $\mathrm{HP}$, but not of $\mathrm{Fb}$ from DIF patients or CO (Fig. 1a and b). However, as described also by others, ${ }^{27}$ AM supernatants from SA patients, when tested on normal lung fibroblasts, either inhibit or enhance their proliferation, and no clear pattern of response could be concluded. These results may indicate that our autologous culture setup may approximate the in vivo situation.

As SA and HP are two diseases where irreversible deterioration in pulmonary function occurs in only $20 \%$ of patients, we hypothesize that inflammatory mediators secreted by AM or Fb may mediate the suppression in the proliferative capacity of autologous $\mathrm{Fb}$ in $\mathrm{SA}$ and $\mathrm{HP}$. We found here and in previous studies ${ }^{21,28}$ that IL-1 is actively secreted from AM in SA and HP patients. Thus, the secretion of IL1 together with secretion of TNF $\alpha,{ }^{29-31}$ which may possibly mediate the suppression of $\mathrm{Fb}$ proliferation in these diseases. This observation was also confirmed by Elias et al.,3,32

In order to investigate the role of IL-1 in the $\mathrm{Fb}$ suppression we examined first whether exogenous stimuli can potentiate $\mathrm{Fb}$ to generate soluble IL- $1 \alpha$ and $\beta$. We could detect IL- $1 \alpha$ and IL- $1 \beta$ gene transcription in CO or LPS/IL-1 stimulated Fb from CO and SA patients. Subsequently, we found that stimulated and non-stimulated $\mathrm{Fb}$ secrete low detectable levels of both species of IL-1 $(0.12-0.17 \mathrm{ng} / \mathrm{ml})$. The same stimulus induced AM to produce high levels of IL- $1 \alpha$ and $\beta$. These results are in agreement with previous findings ${ }^{33,34}$ demonstrating that stimulated Fb contain more (1-10\%) IL-1 mRNA than LPS-stimulated monocytes, but they produce less detectable IL$1 \beta(<0.04 \%)$. The mechanism of IL-1 secretion is still obscure, as it lacks a signal peptide. A role for plasmin or plasmin-like proteases for the release of IL-1 has been reported in macrophages. ${ }^{35}$ It may be that this enzymatic activity is lacking in $\mathrm{Fb}$. This dichotomy between IL-1 gene transcription and expression of biological activity has already been demonstrated in stimulated macrophages and $\mathrm{Fb}^{36,37}$ and may suggest that IL-1 activity may be regulated at multiple levels, such as transcription, stability of mRNA, translation and post-translational events. In our case, we postulate that one of these regulatory post-transcriptional events may be mediated by prostaglandins, as this mechanism was already demonstrated for normal AM to suppress cytokine production. ${ }^{38}$ In fact, we showed that only fibroblasts recovered from SA and HP patients may be induced to release significant amounts of $\mathrm{PGE}_{2}$ upon stimulation with LPs.

Two points have to be considered concerning the possible involvement of IL-1 in suppressing the proliferative capacity of lung $\mathrm{Fb}$ : (i) Fb from $\mathrm{SA}$ and $\mathrm{HP}$ patients in vivo are exposed to high levels of IL-1 of AM origin; (ii) the exogenous effect of this cytokine may be differential on quiescent versus rapidly proliferating fibroblasts. In fact, we tested the effects of exogenous IL- $1 \beta$ on the proliferation of normal $\mathrm{Fb}$, as well as Fb cells obtained from SA and HP patients.

Our results indicate that IL-1 $\beta$, at the levels equivalent to those present in the microenvironment in the lungs of SA and HP patients $(0-4 \mathrm{ng} / \mathrm{ml})$, exerts a suppressive effect on slowly subconfluent proliferating alveolar $\mathrm{Fb}$ from these diseases, whereas at levels detected in normal lungs $(0-0.2 \mathrm{ng} / \mathrm{ml})$, enhance the replication of actively proliferating $\mathrm{Fb}$ recovered from control lungs (Fig. $3 \mathrm{a}-\mathrm{c}$ ). Similar dichotomic effects have already been demonstrated for the regulation of fibroblast proliferation by recombinant interferons $\sigma, \alpha$ and $\beta .{ }^{8}$ Indeed, using $\mathrm{Fb}$, as well as other cell types, contrasting effects of IL- 1 on cell proliferation were reported. ${ }^{39-43}$ This may result from differential sensitivity of various cells to the direct mitogenic effects of IL-1 or to a distinct cytokine cascade induced by IL-1. In our case, it may be possible that IL-1 induces in SA and HP, Fb suppressive cytokines (such as TGF- $\beta$, IL- 6 and possibly IL10) or other mediators (such as $\mathrm{PGE}_{2}$ ).

In conclusion, we postulate that the benign course of the disease of most patients with SA and HP involves a downregulation in the proliferative capacity and possibly alters the secretory function of $\mathrm{Fb}$. 


\section{References}

1. Bitterman PB, Rennard SI, Hunnighake GW, Crystal RG. Human alveola macrophage growth factor for fibroblasts; regulation and partial characterization J Clin Invest 1982; 70: 806-822.

2. Leslie CC, Musson RA, Henson PM. Production of growth factor activity for fibroblasts by human monocyte derived macrophages. J Leuk Biol 1984; 36: 143-159.

3. Elias JA, Rossman MD, Zurier RB. Human alveolar macrophage inhibition of lung fibroblast growth: a prostaglandin-dependent process. Am Rev Respir Dis 1985; 131: 94-99.

4. Elias JA. Tumor necrosis factor interacts via Elias, interleukin-1 and interferons to inhibit fibroblast proliferation via fibroblast prostaglandin-dependent and independent mechanism. Am Rev Respir Dis 1988; 138: 652-658.

5. Bauman MD, Jetten AM, Brody AR. Biologic and biochemical characterization of a macrophage derived growth factor for rat lung fibroblasts. Chest 1987; 91: 15S-16S.

6. Schmidt JA, Oliver CN, Lepe-Zuniga JL, Green I, Gery I. Silica-stimulated monocytes release fibroblast proliferation factor identical to interleukin-1. J Clin Invest 1984; 73: 1462-1472.

7. Martinet Y, Bitterman PB, Mornex JF, Grotensdorst GR, Martin GR, Crystal RG Activated human monocytes express the c-sis proto-oncogene and release a mediator showing PDGF-like activity. Nature 1986; 319: 158-160.

8. Lamontagne L, Gauldie J, Stadnyk A, Richards C, Jenkins E. In vivo initiation of unstimulated in vitro interleukin-1 released by alveolar macrophages. Am Rev Respir Dis 1985; 131: 326-330.

9. Khallil N, Bereznay O, Sporn M, Grennberg AH, Macrophage production of transforming growth factor $\beta$ and fibroblast collagen synthesis in chronic pulmonary inflammation. $J$ Exp Med 1989; 170: 727-737.

10. Piguet PF, Collart MA, Grau GE, Kapanci Y, Vasalli P. Tumor necrosis factor/ cachectin plays a key role in bleomycin induced pneumopathy and fibrosis. $J$ Exp Med 1989; 170: 655-663

11. Huliel M, Douvdevani A, Segal S, Apte RN. Regulation of interleukin 1 generation in immune-activated fibroblasts. Eur J Immunol 1990; 20: 731-738.

12. Huliel M, Douvdevani A, Segal S, Apte RN. Different regulatory levels involved in the generation of hemopoietic cytokines (CSFs and IL-6) in fibroblasts stimulated by inflammatory products. Cytokine 1993; 5: 47-56

13. Elias JA, Reynolds MM, Kotloff RM, Kern JA. Fibroblast interleukin 1 $\beta$ : synergistic stimulation by recombinant interleukin 1 and tumor necrosis factor and posttranscriptional regulation. Proc Natl Acad Sci 1989; 86: 6171-6175.

14. Elias JA, Gustilo, Baeder W, Freudlich B. Synergistic stimulation of fibroblas prostaglandin production by recombinant interleukin-1 and tumor necrosis factor. J Immunol 1987; 138: 3812-3816.

15. Le J, Weinstein $\mathrm{D}$, Gubler V, Vicek J. Induction of membrane associated interleukin-1 by tumor necrosis factor in human fibroblasts. J Immunol 1987; 138: 2137-2142.

16. Laeson CG, Zacharie CO, Oppenheim JJ, Matsushima K. Production of monocyte chemotactic and activating factor (MCAF), by human dermal fibroblasts in response to interleukin 1 or tumor necrosis factor. Biochem Biophys Res Commun 1989; 160 1403-1408.

17. Yoshimura T, Leonard JEJ. Secretion of human fibroblasts of monocyte chemoattractant protein-1, the gene product of gene JE. J Immunol 1990; 144 2377-2383.

18. Rollins BJ, Stier P, Ernst T, Wong CG. The human homolog of the JE gene encodes a monocyte secretory protein. Mol Cell Biol 1989; 9: 4687-4695

19. Rolfe MW, Kunkel SL, Standiford TJ, Censue SW, Allen RM, Evanoff HL, Phan SH, Streiter RM. Pulmonary fibroblast expression of IL-8: a model for alveola macrophage-derived cytokine networking. Am J Respir Cell Mol Biol 1991; 5 493-501.

20. Fireman E, Ben Efraim S, Messer G, Dabush S, Greif J, Topilsky M. Cell-free supernatants of sarcoid alveolar macrophages suppress proliferation of sarcoid alveolar fibroblast. Clin Immunol Immunopathol 1991; 59: 368-378.

21. Fireman E, Ben Efraim S, Greif J, Alguetti A, Ayalon D, Topilsky M. Suppressive activity of alveolar macrophages and blood monocytes from interstitial lung diseases: role of released soluble factors. Int J Immunopharmacol 1989; 7: 751-760.

22. Jordana M, Schulman J, McSharry C, Irving LB, Newhouse MT, Jordana G, Gauldie $\mathrm{J}$. Heterogenous proliferative characteristics of human adult lung fibroblast lines and clonally derived fibroblasts from control and fibrotic tissue. Am Rev Respir Dis $1988 ; 137 ; 579-584$

23. Raghu G, Chen Y, Rusch V, Rabinovitch PS. Differential proliferation of fibroblasts cultured from normal and fibrotic human lungs. Am Rev Respir Dis 1988; 138 703-708.

24. Mekori YA, Huleihel M, Baram D, Apte RN. Depressed IL-1 production by chronic GVHD dermal fibroblasts. Eur Cytokine Net 1990; 2: 77-83.

25. Bucala C, Ritchlin C, Winchester R, Cerami A. Constitutive production of inflammatory and mitogenic cytokines by rheumatoid synovial fibroblasts. J Exp Med 1991 173: 569-574

26. Davis GS, Moehring JM, Absher PM, Brody AR, Kelly J, Low RB, Green GM. Isolation and characterization of fibroblasts obtained by pulmonary lavage of human subjects. In vitro 1979; 15: 612-623.

27. Elias JA, Rossman MD, Daniele RP. Blood and lung mononuclear cell inhibition of fibroblast growth in sarcoidosis. Am Rev Respir Dis 1984; 130: 1050-1058.

28. Hunnighake GW. Release of interleukin-1 by alveolar macrophages of patients with active pulmonary sarcoidosis. Am Rev Respir Dis 1984; 129: 569-572.

29. Strasz J, Mannel DN, Pfeofer S, Bokowski A, Ferlinz F, Quernheim JM. Spontaneou monokine release by alveolar macrophages in chronic sarcoidosis. Int Arch Allergy Appl Immunol 1991; 96: 68-75.

30. Fireman E, Aderka D, Ben Efraim S, Greif J, Wallach D, Topilsky M. Suppressive effect of TNF $\alpha$ and IL-1 on alveolar fibroblast proliferation in sarcoidosis. Mediator of Inflammation 1992; 1: 235-240.

31. Denis M, Cournier Y, Fournier M, Tardif J, Laviolette M. Tumor necrosis factor plays an essential role in determining hypersensitivity pneumonitis in mouse model. $A m$ J Respir Cell Mol Biol 1991; 5: 477-483.

32. Elias JA, Freundlich BB, Kern JA, Rosenbloom J. Cytokine networks in the regulation of inflammation and fibrosis in the lung. Chest 1990; 97: 1439-1445.

33. Rochemonteix-Galve B, Dayer JM, Junod AF. Fibroblast-alveolar cell interactions in sarcoidosis and idiopathic pulmonary fibrosis; evidence for stimulatory and inhibitory cytokine production by alveolar cells. Eur Respir J 1990; 3: 653-664.

34. Kern JA, Lamb RJ, Reed JC, Daniele RP, Nowell PC. Dexamethasone inhibition of interleukin-1 $1 \beta$ production of human monocyte: posttranscriptional mechanisms. J Clin Invest 1988; 81: 237-244

35. Matsushima K, Taguchi M, Kovacs EJ, Young HA, Oppenheim JJ. Intracellula localization of human monocyte associated interleukin-1 activity and release of biologically active IL-1 from monocytes by trypsin and plasmin. J Immunol 1986, 136: 2883-2891.

36. Dinarello CA, Wolff SK. Mechanism of disease: the role of interleukin 1 in disease N Engl J Med 1992; 328: 106-113

37. Douvdevani A, Mahmud M, Segal HS, Apte RN. Aberrations in interleukin-1 expression in oncogene-transformed fibrosarcoma lines: constitutive interleukin-1a transcription and manifestation of biological activity. Eur Cytokine Net 1991; 2 257-264.

38. Kundsen PJ, Dinarello CA, Strom TB. Prostaglandin posttranscriptionally inhibit monocyte expression of interleukin-1 activity by increasing intracellular cyclic adenosine monophosphate. J Immunol 1986; 137: 3189-3194.

39. Schmidt JA, Mizel SB, Cohen D, Green I. Interleukin 1, a potential regulator of fibroblast proliferation. J Immunol 1982; 128: 2177-2182.

40. Rosenwasser LJ, Dinarello CA. Ability of human leukocytic pyrogen to enhance phytohemaglutinin-induced murine thymocyte proliferation. Cell Immunol 1981, 63: 134-142.

41. Libby P, Friedman GB, Salomon RN. Cytokines as modulators of cell proliferation in fibrotic diseases. Am Rev Respir Dis 1989; 140: 1114-1117.

42. Fujiwara H, Kleinhenz ME, Wallis RS, Ellner JJ. Increased interleukin-1 production and monocyte suppressor cell activity associated with human tuberculosis. Am Rev Respir Dis 1986; 133: 73-77.

43. Floege J, Topley N, Hoppe J, Barret TB, Resch K. Mitogenic effect of plateletderived growth factor in human glomerular mesengial cells: modulation and/o suppression by inflammatory cytokines. Clin Exp Immunol 1991; 86: 334-341.

Received 16 June 1994;

accepted in revised form 5 August 1994 


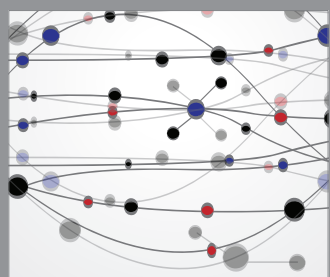

The Scientific World Journal
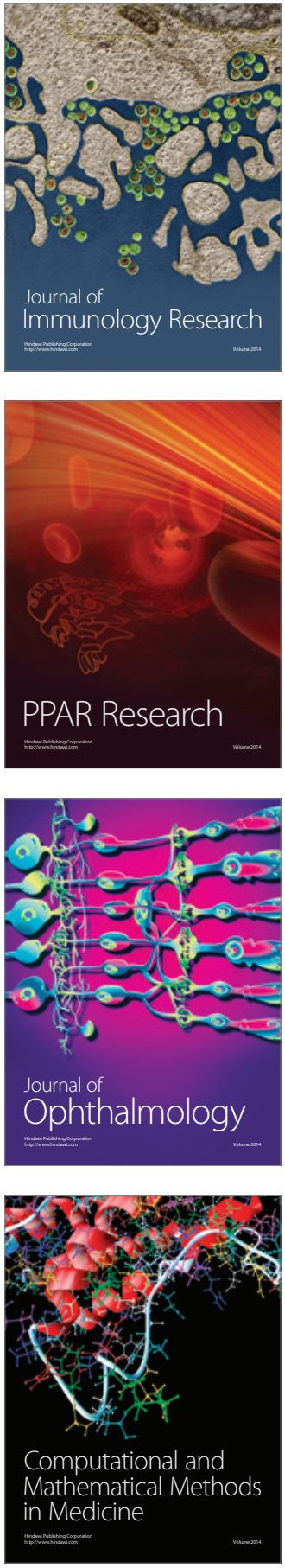

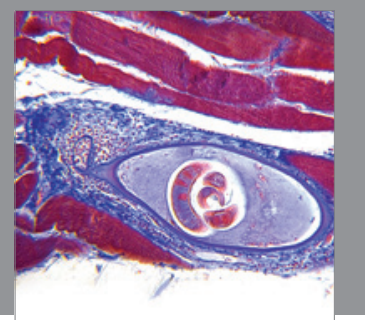

Gastroenterology

Research and Practice
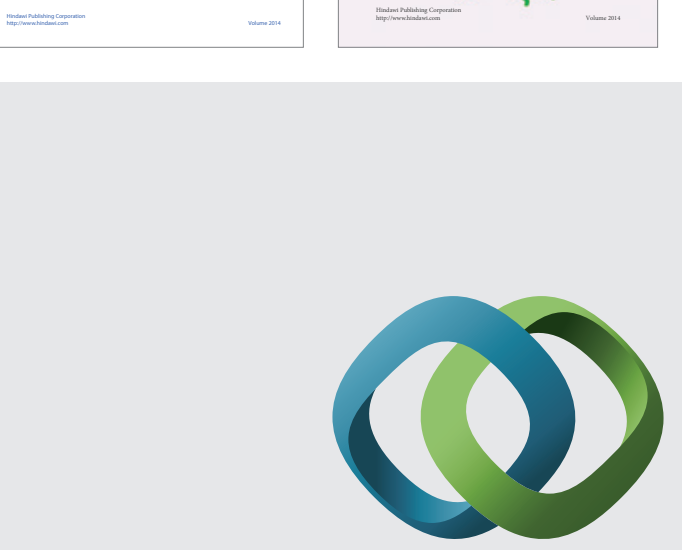

\section{Hindawi}

Submit your manuscripts at

http://www.hindawi.com
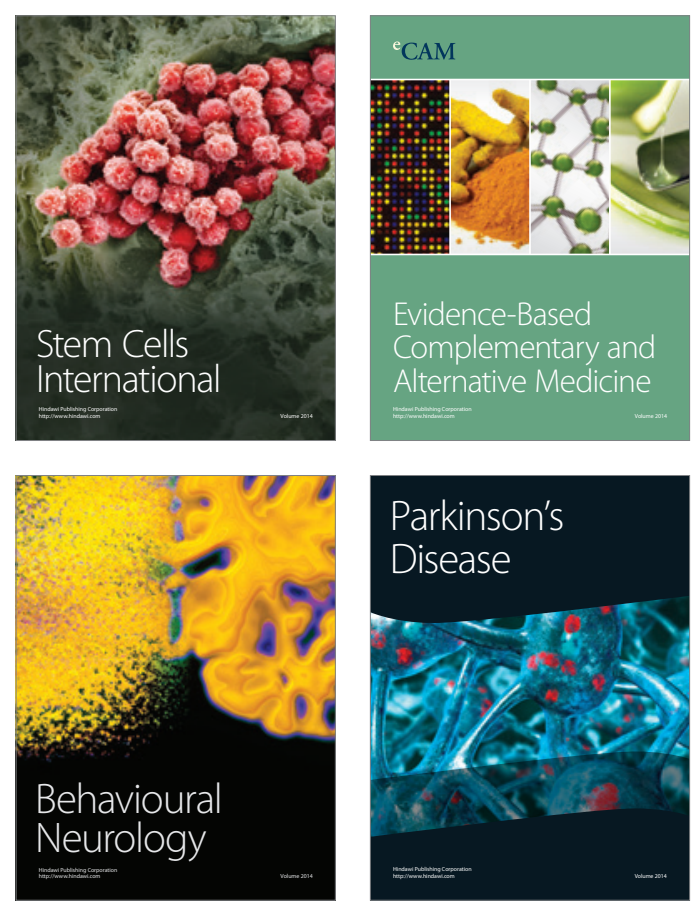

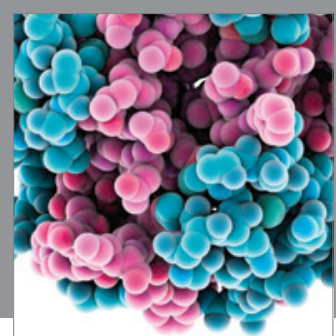

Journal of
Diabetes Research

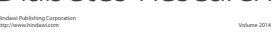

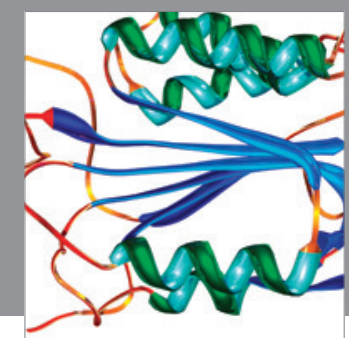

Disease Markers
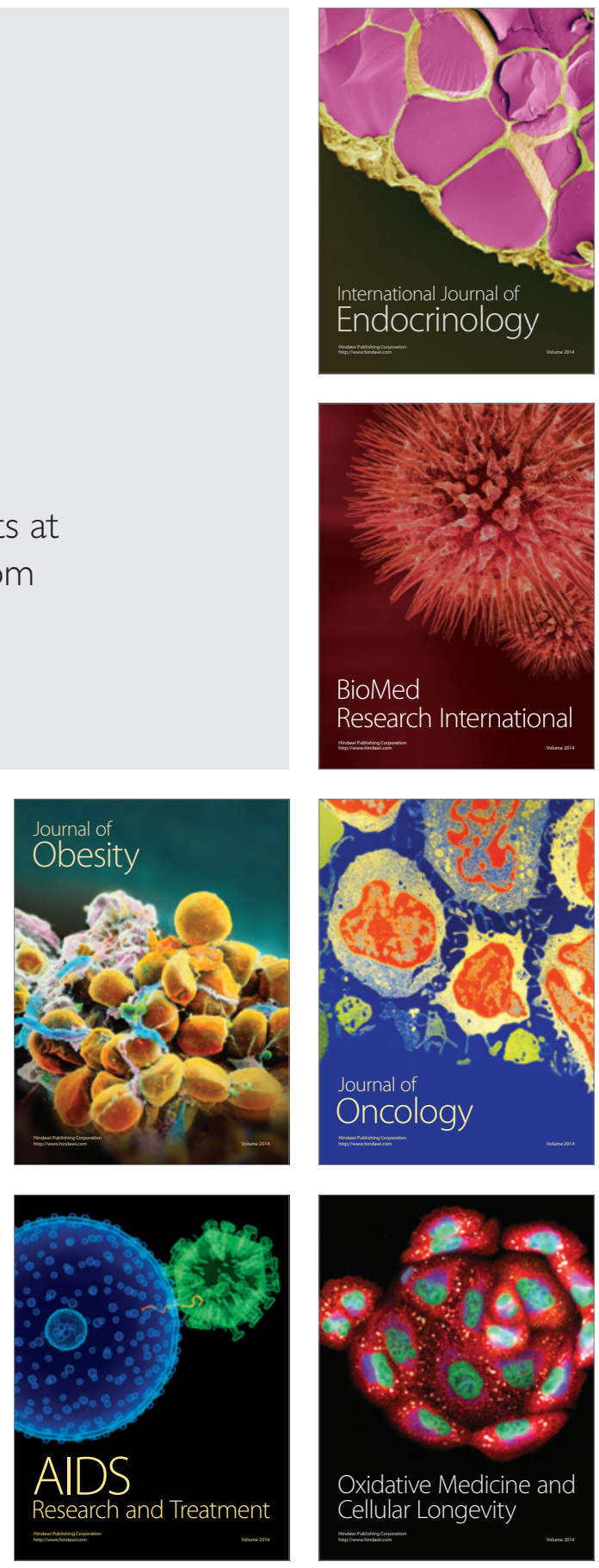